\title{
Quem é quem? Um estudo antroponímico a partir dos sobrenomes do município de Lajeado - RS
}

\author{
Who is Who? An anthroponymy study of surnames in the county of Lajeado - RS
}

\begin{abstract}
Kleber Eckert*
RESUMO: O presente artigo propõe-se a fazer um estudo antroponímico a partir dos sobrenomes mais comuns do município de Lajeado - RS. Para tanto, fez-se um levantamento dos 20 sobrenomes que ocorrem com mais frequência na lista telefônica do município, os quais foram divididos por origem étnica e analisados histórica e etimologicamente. Além disso, discutem-se também questões relacionadas à onomástica e, dentro dela, a antroponímia.
\end{abstract}

PALAVRAS-CHAVE: Antroponímia; sobrenomes; Lajeado - RS; origem étnica.

ABSTRACT: This paper proposes an anthroponymic study of the most common surnames presented in the county of Lajeado - Rio Grande do Sul State, in Brazil. A survey presenting the 20 surnames that appear in the telephone directory of the county was carried out. The surnames were divided into ethnic origin and historically and etymologically analyzed. Issues related to anthroponomy in the onomastics field were also discussed.

KEYWORDS: Anthroponomy; surnames; Lajeado - RS; ethnic origin.

\section{Introdução}

O presente artigo tem por objetivo fazer uma breve análise histórico-etimológica dos sobrenomes que ocorrem com mais frequência no município de Lajeado- $\mathrm{RS}^{1}$ e, a partir das constatações, levantar algumas considerações acerca desses sobrenomes. Para atender ao objetivo da pesquisa, inicialmente, faz-se uma breve síntese sobre aspectos históricos e sócioculturais do município de Lajeado, levando em conta processos imigratórios de formação da comunidade, bem como características atuais do município. Na sequência, propõe-se uma reflexão sobre a onomástica e as relações dessa disciplina com outras áreas do conhecimento. Também se discute a diferença entre nome comum e nome próprio, entre signo linguístico e signo onomástico. Elaboram-se considerações sobre a opacidade e a transparência desse signo,

\footnotetext{
${ }^{*}$ Mestre em Letras, Cultura e Regionalidade pela Universidade de Caxias do Sul - UCS. Doutorando em Letras pela mesma instituição.

${ }^{1}$ O município de Lajeado, que se emancipou de Estrela em 1891, localiza-se na região do Vale do Taquari, a 110 $\mathrm{km}$ da capital, Porto Alegre. A cidade possui em torno de 71.000 habitantes (Censo de 2010) e uma área territorial de 90 km2. Já como município mãe, Lajeado deu origem a 11 novos municípios, a saber: Guaporé, Encantado, Arroio do Meio, Cruzeiro do Sul, Boqueirão do Leão, Progresso, Santa Clara do Sul, Sério, Marques de Souza, Forquetinha e Canudos do Vale. Fonte: www.ibge.gov.br. Acesso em 02 de jan. de 2013.
} 
a partir de estudos de Dauzat (1950), Guérios (1973), Dick (1992), Seabra (2008) e Marcato (2009).

Especificamente na área da antroponímia, que estuda o patrimônio dos nomes pessoais, são feitas ponderações acerca dos aspectos linguísticos, psicológicos e sociais dos nomes próprios; além disso, efetua-se o reconhecimento dos tipos de nomes e/ou sobrenomes quanto à sua origem. Após, levantam-se aspectos históricos sobre o surgimento dos sobrenomes europeus e propõem-se diferentes perspectivas de análise, sejam elas linguísticas ou extralinguísticas, com base em princípios teóricos de Dauzat (1950), Guérios (1973), Dick (2000), Carvalinhos (2007), Marcato (2009) e Mioranza (2009).

Em relação à metodologia de pesquisa, primeiramente foram listados todos os sobrenomes, restringindo o estudo àqueles de pessoas físicas, presentes na lista telefônica de Lajeado-RS, referente ao ano de 2012. A escolha da lista telefônica deu-se com base em outros estudos antroponímicos, tais como os citados por Marcato (2009) e Rossebastiano e Papa $(2005)^{2}$. De posse dos dados da lista telefônica, os sobrenomes foram lançados em planilhas Excel (ao lado de cada sobrenome, registrava-se a quantidade de ocorrências) e ordenados por números absolutos, até chegar àqueles com maior frequência. Os 20 sobrenomes mais comuns ainda foram classificados segundo a origem étnica: portuguesa, alemã e italiana, já que esses três foram os grupos étnicos que tiveram maior incidência na colonização da região do Vale do Taquari, onde está localizada a cidade de Lajeado.

De posse dos 20 sobrenomes mais frequentes, tentou-se fazer uma classificação tipológica e uma análise da etimologia de cada um deles, além de um levantamento histórico sobre a origem de cada sobrenome em relação a seu uso no Brasil e no Rio Grande do Sul. Para fazê-lo, serviram de embasamento estudos de Guérios (1973), Klering (1988) e Barata e Bueno (1999), principalmente.

\section{Caracterização da localidade: o município de Lajeado-RS}

O território onde hoje está localizado o município de Lajeado foi habitado, inicialmente, por aborígenes ibiraiaras, pertencentes à tribo indígena Ibiaçá, conforme Shierholt (1995, p. 13). Os primeiros registros da localidade remontam ao início do século XIX, quando Lajeado

\footnotetext{
${ }^{2}$ Marcato (2009), Rossebastiano e Papa (2005) citam um estudo realizado por De Felice em 1982, no qual o pesquisador chega aos trinta nomes masculinos e femininos mais utilizados na Itália a partir de levantamentos realizados através da lista telefônica de 1981.
} 
era chamada de Conventos Velhos, sua primeira denominação oficial. Na época, os irmãos João e José Inácio Teixeira receberam sesmarias, que foram divididas em fazendas.

A partir do ano de 1853, terras compradas pela Companhia Batista Fialho de Vargas foram medidas pelo agrimensor alemão Carl Ernst Mützel, com o intuito de serem vendidas em pequenos lotes para os vindouros colonos alemães e seus descendentes (SECULTUR, 1997, p. 04). Portanto, o princípio da ocupação do território de Lajeado deu-se, no início do século XIX por descendentes de portugueses e, meio século mais tarde, pelos alemães. É o que está evidenciado nos dados históricos que constam no site do IBGE: "Em 1858, já cultivavamo solo 188 pessoas, dos quais 112 alemães. O relatório de Baptista, Fialho \& Cia , em 1860, mencionava 231 colonos, sendo 145 alemães".

A partir de então, a localidade começou a se desenvolver, tanto que em 1875 foi elevada à categoria de sede distrital. Anos mais tarde, com a lei provincial de 26 de maio de 1881 , a Freguesia de Santo Inácio dos Conventos foi estabelecida e instalada. Finalmente, pelo ato estadual $\mathrm{n}^{\circ} 57$, de 26 de janeiro de 1891, o município de Lajeado foi criado, o que era um pedido da população da época, que girava em torno de 18.000 habitantes (Fonte: www.ibge.gov.br. Acesso em 02 de jan. de 2013).

Depois do processo de emancipação, começou a imigração de colonos italianos e seus descendentes para a parte de Lajeado que era chamada de "Zona Alta", que atualmente compreende os municípios de Progresso, Sério, Boqueirão do Leão, Pouso Novo, Nova Bréscia, Capitão, Encantado, Muçum e parte dos municípios de Marques de Souza e Travesseiro (Fonte: www.ibge.gov.br. Acesso em 02 de jan. de 2013). Esse processo migratório é destacado por Frosi e Mioranza (2009):

Nessa mesma década, inicia-se a ocupação espontânea das terras de Encantado. [...] Da Colônia Dona Isabel, de modo particular, deslocam-se grupos de imigrantes em demanda das terras de Encantado, de tal modo que no início do século XX, às margens do Taquari, a nova Colônia Encantado inicia sua expansão em direção ao norte... (p. 51).

Assim, diante do quadro de ocupação do território por portugueses, alemães e italianos, mostram-se alguns valores culturais trazidos pelos antepassados e que são mantidos até hoje. Como exemplos, os grupos de danças folclóricas, as bandas, os corais comunitários, as sociedades comunitárias de lazer, entre outras. Já na atualidade, somam-se a esses valores, os Centros de Tradições Gaúchas - CTG's, que estão espalhados por todo o município (SECULTUR, 1997). 
Atualmente, Lajeado é a maior cidade da região do Vale do Taquari, e por isso é conhecida como Capital do Vale. O município polo atrai empresas, trabalhadores e estudantes dos municípios adjacentes e, inclusive, de outras regiões. É a cidade da região que possui uma indústria diversificada, com forte tradição da produção de alimentos, móveis e pedras preciosas. Ademais, há uma expansão acelerada na oferta de serviços e na construção civil (SECULTUR, 1997).

É o que também pode ser percebido nas palavras do historiador Shierholt, quando qualifica o município de Lajeado em relação à região onde ele está situado:

Entrecortada pelas rodovias BR 386, RS 130 e a Rota do Sol, a localização de Lajeado na região é privilegiada. A diversidade na produção da pequena propriedade rural, a variedade na indústria e no comércio, e o espírito cosmopolita dos lajeadenses atraem migrantes, ampliam opções econômicas, integram etnias e transformam Lajeado num polo político, educacional, cultural e econômico regional, a capital do Vale do Taquari (SHIERHOLT, 2000, p. 92).

\section{A onomástica}

A onomástica é um ramo da lexicologia que estuda a origem e a formação dos nomes próprios. O termo, de origem grega, é formado pelos elementos onoma (nome) e tékne (arte), cujo resultado é onomastiké, que significa a arte de nomear. A forma grega aparece no latim tardio como onomasticon, que evolui e chega ao Português como onomástica ${ }^{3}$. De acordo com Mioranza (2009), o vocábulo foi usado, por um longo período de tempo, para indicar o estudo de todos os nomes próprios, seja de pessoas, seja de lugares. A disciplina está em constante diálogo com outras áreas da linguística, dentre elas, com a linguística histórica que

estuda as raízes antigas e distantes que propiciaram o surgimento e a fixação dos nomes e sobrenomes. Essa parte da linguística, que busca origens e remonta aos vocábulos antigos, é chamada de etimologia. Os estudos etimológicos se voltam, portanto, sempre para o passado e procuram interpretar não somente as raízes lexicais como também todo o contexto histórico e social em que elas surgiram (MIORANZA, 2009, p. 27).

A disciplina possui dois grandes campos de investigação, que são, conforme Marcato (2009), a toponímia e a antroponímia. A primeira, também conhecida como antroponomástica,

\footnotetext{
3 Segundo Guérios (1973), a onomástica, que é a ciência dos nomes próprios, também pode ser chamada de onomatologia.
}

(C) Kleber Eckert, p. 139-159 
é a que se ocupa dos nomes próprios de pessoa, isto é, os antropônimos. A segunda, chamada também de toponomástica, é a que se refere aos estudos dos nomes de lugar, ou seja, os topônimos.

A divisão da disciplina em duas grandes áreas também é apresentada por Guérios (1973), ao afirmar que

$\mathrm{O}$ estudo dos nomes próprios classificam-no primordialmente em nomes de pessoas, a que se dá o título de Antroponímia (expressão que pela primeira vez foi empregada por J. Leite de Vasconcelos na Revista Lusitana, I, 45), e em nomes de lugares ou geográficos, que se denomina Toponimia (nomes de nações, províncias, cidades, sítios, montanhas, vales, rios, etc.) (1973, p. 15, grifos do autor).

Em relação a essa divisão, Seabra (2008) pondera que as duas grandes áreas são formadas por "elementos linguísticos que conservam antigos estágios denominativos" (p. 1945). É o que também esclarece Dauzat (1950), quando defende que tanto os nomes de pessoas quanto os de lugares sofrem os mesmos fenômenos de cristalização e de esterilização linguísticas. $\mathrm{O}$ autor alerta, no entanto, que os primeiros são bem menos arcaicos que os segundos, uma vez que

o aspecto do solo, as montanhas, os rios e zonas ribeirinhas permanecem fixos durante dois ou três milênios de história; a cidade, a aldeia duram mesmo durante séculos. Ao contrário, as gerações se sucedem rápidas, favorecendo as mudanças e o desaparecimento de nomes, sobretudo no decurso de períodos turbulentos. [...] as variações de moda, tão poderosas para os nomes de pessoas, não tiveram quase nenhuma influência sobre os nomes de lugares (DAUZAT, 1950, p. 05)

A respeito da importância dos estudos onomásticos, Dick (1992) defende que tanto a antroponímia quanto a toponímia

ultrapassam, em muito, a conceituação teórica que lhes é atribuída, tornandose nas Ciências Humanas, fontes de conhecimento tão excelentes quanto as melhores evidências documentais. São, por assim dizer, verdadeiros registros do cotidiano, manifestado nas atitudes e posturas sociais que, em certas circunstâncias, a não ser deles, escaparia às gerações futuras (DICK, 1992, p. 178).

\footnotetext{
${ }^{4}$ As traduções do francês e do italiano para o português, constantes neste texto, foram realizadas pela professora Vitalina Maria Frosi, da Universidade de Caxias do Sul - UCS.
} 
Assim, o estudo dos nomes próprios leva-nos a questionar acerca da diferença entre nome comum e próprio. Em relação a esse questionamento, Marcato (2009) problematiza a discussão afirmando que o impasse consiste em identificar um sistema de nomes próprios com relação a um sistema de nomes comuns, já que o objeto de estudo da onomástica são os nomes próprios.

Na mesma linha de reflexão, Guérios (1973) afirma que a distinção entre o nome próprio e o comum é artificial na perspectiva do linguista, pois na sua origem, seja ela remota ou não, todos os nomes próprios eram nomes comuns. Apesar da aparente artificialidade, segundo o autor, existe uma distinção real e concreta:

Todos os vocábulos ou signos possuem "alma", i. é, sentido ou significado, e "corpo" ou significante, que é, na linguagem falada, o som, e na linguagem gráfica a escrita. Ora, os nomes próprios não lembram hoje, no intercâmbio linguístico, os sentidos que despertavam outrora na sua origem, nem lembram outros, donde se conclui que são vocábulos desprovidos de "alma", ou melhor, ficaram "petrificados"; apenas conservaram o "corpo" ou significante (GUÉRIOS, 1973, p. 15-16, grifos do autor).

De maneira muito semelhante, Marcato (2009) alerta que nem sempre a onomástica é vista como pertencente à linguística. Ela $\mathrm{O}$ diz porque o nome próprio não é considerado totalmente um signo linguístico, exatamente pela "falta (ou a debilidade) do significado que é uma parte (a outra é o assim chamado significante) de que é composto um signo linguístico" (p. 18).

A autora ainda complementa a reflexão ao justificar por que o signo onomástico é considerado uma etiqueta ou um rótulo:

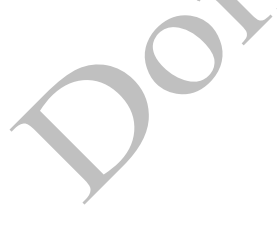

Com relação a um signo linguístico, o signo onomástico é formado por um significante, uma entidade fônica que se reporta diretamente a um indivíduo, que tem a função de identificar um indivíduo no interior de uma coletividade, sem a passagem por um significado relativo a um elemento ou objeto, individual e concreto, isto é, a um "referente" (MARCATO, 2009, p. 19).

Marcato $(2009$, p. 18) traz à discussão os conceitos de opacidade e transparência do signo onomástico. Para a autora, um signo transparente existe quando, ao nome próprio, há a possibilidade de associar elementos do vocabulário de dada língua, que é o que ocorre no italiano com Monte Bianco, por exemplo. Por outro lado, quando essa possibilidade inexiste, é porque o signo onomástico foi criado numa época remota, quando no território em que ocorre 
esse signo falava-se outra língua, como ocorre com o topônimo Verona. Neste último caso, dizse que o signo é opaco.

Na mesma perspectiva, Seabra (2008) explica como se dá a opacidade do signo onomástico. Para a pesquisadora, "a pessoa identifica alguém ou uma determinada localidade sem, entretanto, atribuir-lhe um significado, preserva o referente mas não preserva a informação. É assim que os topônimos e os antropônimos mais comumente permanecem na língua" (p. 1951).

Embora com outras palavras, Guérios (1973, p. 16) também discute a opacidade e a transparência do signo onomástico. O exemplo de signo opaco é o antropônimø Licurgo, que atualmente não lembra o primitivo caçador de lobos. Já um exemplo de signo transparente é o topônimo Bahia, uma vez que uma localidade que assim se chama pode traduzir, de fato e na atualidade, uma baía.

Por toda a complexidade que envolve a semântica do nome próprio, é preciso examinálo levando em conta também uma perspectiva extralinguística, seja ela diacrônica ou sincrônica (MARCATO, 2009). Além disso, é preciso considerar a onomástica num diálogo com outras áreas, fora da linguística, tais como a antropologia, a sociologia, a geografia, a história e a psicologia (MIORANZA, 2009).

\subsection{A antroponímia}

A parte da onomástica que se dedica ao estudo dos nomes de pessoas, como já afirmado anteriormente, é a antroponímia. O estudo dos antropônimos é, consoante Carvalinhos (2007), visto com importância apenas nos meios acadêmicos, apesar de o nome ser algo comum do nosso dia a dia. Para a pesquisadora, "o nome próprio tem como função registrar atitudes e posturas sociais de um povo, suas crenças, profissões, região de origem, entre outros aspectos" (p. 02).

Nos estudos antroponímicos, inclui-se o estudo dos nomes, dos sobrenomes e também dos apelidos. Marcato (2009, p. 29) alega que o patrimônio dos nomes pessoais é resultado de nomes históricos, por um lado, e por outro, pode ser motivado por modas de momento. Já para Carvalinhos (2007), a motivação antroponímica, atualmente, pode ser considerada uma questão de fé, por uma parte, e por outra, de influência televisiva, já que "a tendência da grande massa da população brasileira é nomear suas crianças com o nome do(a) herói/heroína da novela que 
está sendo exibida com grande sucesso; em homenagem a seu santo ou santa de devoção, ou em agradecimento por uma graça alcançada" (p. 02).

Marcato, para quem "o nome tem a função de uma etiqueta, serve para identificar um indivíduo em si, absolutamente, em referência a todos os outros que formam a coletividade" (2009, p. 30), apresenta uma diferença em relação ao sistema dos sobrenomes e dos nomes. Enquanto o sistema daqueles só se modifica de forma muito limitada, o sistema destes é flexível e pode mudar continuamente. Para a autora, pode-se perceber essa modificação pelos novos nomes que entram em uso por modas onomásticas e outros que são abandonados na passagem das gerações.

Tanto para Dauzat (1950) quanto para Guérios (1973), os antropônimos, sejam eles nomes ou sobrenomes, podem ser estudados em duas perspectivas principais: sob o aspecto linguístico e sob o aspecto psicológico e social. O interesse linguístico reside no fato de os antropônimos oferecerem, em todas as épocas, fatos de estratificação e de esterilização, tanto que Dauzat (1950) afirma que são “fósseis da língua, restos de leitos históricos submersos pelos contributos sucessivos das sedimentações lexicais, eles permitem reconstituir formas e tipos desaparecidos da fala corrente" (p. 9).

Quanto ao aspecto psicológico e social, os antropônimos carregam consigo marcas de civilizações passadas ou então "refletem as civilizações passadas com todas as suas instituições. Os nomes são criados sob o influxo religioso, político, histórico, etc., de circunstâncias variadíssimas, e em que transparece viva a alma popular de todos os tempos e de todos os lugares" (GUÉRIOS, 1973, p. 18).

Ademais, para Dauzat (1950), com os nomes de pessoas é possível entrar no cerne da alma popular de épocas passadas. O autor complementa que esses nomes são símbolos vivos de crenças e de superstições hoje desaparecidas. Perspectiva semelhante é apresentada por Carvalinhos (2007), para quem o nome das pessoas é "um manancial rico para conhecimento não apenas da língua, mas também permite apreender um pouco da cultura, religião e até ideologia do povo que o criou em determinada época" (p. 16).

Ainda numa perspectiva histórica, Carvalinhos (2007) defende que, na língua portuguesa, por exemplo, a história do nome está estreitamente vinculada à própria história da língua.

Os nomes medievais (período das Navegações) provêm, naturalmente, dos nomes adotados pelos povos que habitavam a Península, lusitanos e hispanos, 
dominados e influenciados pelos fenícios, gregos e em seguida pelos romanos que, por sua vez, cederam o território aos povos germânicos (já latinizados) e posteriormente aos árabes (CARVALINHOS, 2007, p. 7).

Dauzat (1950) apresenta uma divisão trinária acerca da origem primeira dos nomes de pessoas:

Denominações de ordem mística, cujos prenomes emprestados à hagiografia são a última metamorfose. Denominações de origem tiradas da moradia, da propriedade, do país, do lugar, ou até mesmo da época do nascimento: muitos patronímicos e muitos apelidos vêm da lá. Denominações causadas pelo aspecto psíquico, o caráter do indivíduo, sua profissão ou seus hábitos: a fonte mais abundante de apelidos que são a origem da maioria dos nomes de família (DAUZAT, 1950, p. 13).

Já a origem da formação da maioria dos sobrenomes europeus remonta à Idade Média. $\mathrm{Na}$ Itália, por exemplo, eles se fixaram a partir de apelidos e outros elementos que eram acrescentados ao nome pessoal. Eles também são chamados de nomes de família, e pode-se dizer que são transmitidos ao longo de uma linha de descendência e que têm a função de distinguir um indivíduo em relação aos demais que formam uma coletividade (MARCATO, 2009).

Sobre a diferença entre o sobrenome e o nome (ou prenome), Dick (2000) afirma que

Transmitido de geração a geração, o nome ou o apelido de família carrega em si todas as marcas da descendência gentílica, não sendo por isso livre escolha dos cidadãos. A imposição obrigatória do que se convencionou chamar, atualmente, de sobrenome, é o seu traço distintivo, em oposição ao prenome, fruto de um ato volitivo dos pais (p. 218).

O sistema binominal moderno (nome + sobrenome), hoje utilizado, surge a partir do sistema nominal romano, que era formado por três elementos. Na época, a fórmula trinômia compreendia o prenome ou nome individual, o nome ou a gens e o sobrenome ou o apelido. $\mathrm{Na}$ época republicana de Roma, o prenome perde sua função de nome individual que passa a ser ocupada pelo nome (MARCATO, 2009).

Séculos mais tarde, entre o IX e o XVI, na Europa românica e germânica “forma-se um novo sistema constituído pelo nome e sobrenome determinado pela fixação de vários tipos de acréscimos, que originariamente têm somente uma função distintiva para evitar as ambiguidades criadas pelas homonímias" (MARCATO, 2009, p. 67, ). 
Acerca da herança histórica dos sobrenomes formados na Idade Média, Mioranza (2009) ratifica o já citado, ao defender que

os sobrenomes surgiram de uma necessidade premente de distinguir os grupos familiares. Eles são vistos, hoje, como herança de uma estrutura nominativa medieval, inserida na sociedade da época. Atravessando os séculos, essa estrutura persiste até hoje, sinal de que a reformulação processada em tempos medievais foi válida e ainda tem sua serventia em nossos dias $(2009$, p. 134$135)$.

Os sobrenomes podem ser classificados em três grandes categorias, considerando-se o que De Felice (1978, apud MARCATO, 2009, p. 80-81) chama de função descritiva. A primeira compreende os nomes de tradição genérica ou não específica, sem conotações socioculturais; os nomes de tradição religiosa; os nomes augurais e gratulatórios de formação medieval; os nomes de tradição douta, literários ou históricos, que foram retomados no fim da Idade Média e no Renascimento.

O segundo grupo é formado por sobrenomes que se originaram de apelidos que realçam características de uma pessoa ou do próprio grupo familiar, com o objetivo de distingui-lo dos demais. Podem ser apelidos de ordem jocosa, satírica, polêmica, depreciativa ou ofensiva, além de referências ao intelecto, ao caráter ou ao comportamento. Como exemplo, no italiano Piccolo (pequeno), no germânico Bruno (que tem olhos ou cabelos castanhos) e no português Branco.

Já a terceira categoria compreende os sobrenomes de origem étnica e toponímica, tais como no italiano Tedesco (alemão) e Milani (Milão); patronímicos e matronímicos, como no português Rodrigues (filho de Rodrigo) e no italiano Di Pietro; nomes de atividades profissionais, como no italiano Fabbro (ferreiro) e no alemão Schneider (alfaiate). Desta última subcategoria, Guérios (1973) apresenta a profissão de cavaleiro "a que correspondem os italianos Cavalcanti, Cavallieri; francês: Chevalier; espanhol: Caballero; port.: Cavaleiro" (p. 25 , grifos do autor).

Também numa perspectiva classificatória, Carvalinhos (2007, p. 8-13) sintetiza, no esquema a seguir, a origem dos sobrenomes: o uso do patronímico, que era o genitivo do nome paterno acrescentado ao nome, como Fernandes (filho de Fernando); os sobrenomes de motivação religiosa, como os epítetos dados a alguns santos (Assis, Sales, Batista); os de origem toponímica (Lago, Ramos, Resende) e os que derivaram de alguma alcunha, tais como mês ou condições de nascimento, profissão, qualidades ou defeitos físicos ou morais. 
Guérios (1973, p. 42) ainda questiona se todas as pessoas que possuem o mesmo sobrenome originam-se de uma só família. O autor busca a resposta apoiado na tese defendida por Leite de Vasconcelos de que é preciso, neste caso, visitar a História e, mais especificamente, a Genealogia, e não tanto a Filologia.

Apelidos [sobrenomes] provindos de patronímicos, [...] não indicam necessariamente parentesco, o que não significa que ele às vezes não exista. [...] Bastava que um indivíduo se chamasse ou chame Rodrigo, para que o filho recebesse ou receba o sobrenome de Rodriguez ou de Rodrigo, depois transmitido como apelido [sobrenome] (GUÉRIOS, 1973, p. 43, grifos do autor).

Opinião semelhante Guérios (1973, p. 43) expressa acerca døs sobrenomes que provêm da geografia, de alcunhas e de línguas estrangeiras. No entanto, a respeito dos sobrenomes portugueses, por exemplo, que ele considera raros ou pouco vulgares, tais como Perantunes, Cirne e Soeiro, parece haver a possibilidade de uma ascendência comum.

Marcato (2009) também levanta a dificuldade em estabelecer relações entre um topônimo, um étnico e um sobrenome, tal como acontece com o sobrenome italiano Cargnello - e suas variantes. Para a autora, o antropônimo "pode vir do étnico claramente conexo com Carnia, região do Fríuli, ou também de um nome relativo a uma atividade que tem como base o termo cargnello (derivado do étnico) 'tecelão', um trabalho que os 'carnienses' praticavam em toda a planície Padana" (MARCATO, 2009, p. 65, grifos da autora).

Outra dificuldade que a autora observa é que o sobrenome, como forma linguística, pode ter sofrido mudanças através da transmissão, sejam elas em nível de língua oral, sejam de tradição escrita. Muitos sobrenomes sofreram modificações por causa de mal entendidos, de adequações à língua oficial e de tendências notariais, e por isso não é em todos os casos que se consegue reconstruir a sua história linguística (MARCATO, 2009).

Finalmente, é preciso atentar-se para a semântica do nome próprio em toda a sua complexidade, examinando-o a partir de diferentes perspectivas, sejam elas linguísticas e extralinguísticas, sincrônicas e diacrônicas. Apesar dessas diferentes perspectivas, haverá sobrenomes que continuarão opacos, uma vez que o significado que eles tinham, quando surgiram, perdeu-se completamente no transcorrer do tempo (MARCATO, 2009). 


\section{Os 20 sobrenomes mais frequentes do município de Lajeado-RS}

A partir dos dados colhidos na lista telefônica do ano de 2012, foram levantados 2.136 sobrenomes diferentes, num total de 7.863 registros. Os 20 sobrenomes mais comuns, que equivalem a 1.223 registros, são: $\operatorname{Silva}^{5}$ (217), $\operatorname{Santos}^{6}$ (128), Mallmann (90), Schneider (85), Oliveira $^{7}$ (77), Schmidt $^{8}$ (71), Becker (55), Souza (52), Scherer (48), Rodrigues (47), Eckhardt (44), Pretto (43), Johann (42), Costa (37), $\operatorname{Rosa}^{9}$ (34), Müller (33), Gerhardt (31), Ferreira (30), Klein (30) e Lopes (29).

Nesses sobrenomes encontram-se 10 de origem alemã (Mallmann, Schneider, Schmidt, Becker, Scherer, Eckhardt, Johann, Müller, Gerhardt e Klein), 9 de origem portuguesa (Silva, Santos, Oliveira, Souza, Rodrigues, Costa, Rosa, Ferreira eLopes) e apenas 1 de origem italiana (Pretto), o que corresponde a 50\%, 45\% e 5\%, respectivamente (Gráfico 01).

Essas ocorrências podem ser analisadas e entendidas a partir da história de colonização do município de Lajeado, uma vez que foifundado por portugueses, e depois colonizado por alemães e seus descendentes. A presença dos descendentes de italianos pode atribuir-se a fluxos de migração interna de regiões colonizadas por italianos, que hoje fazem fronteira com o município de Lajeado.

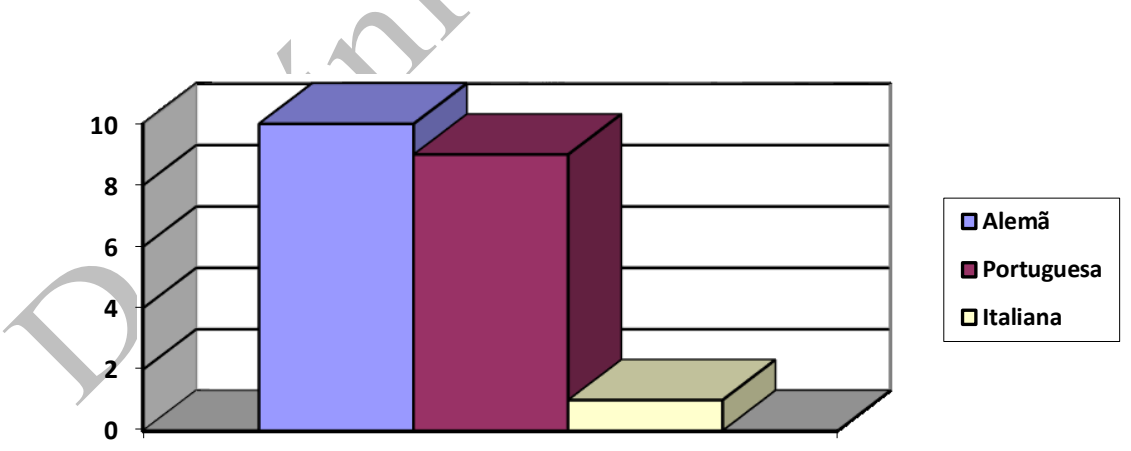

Gráfico 01 - Os 20 sobrenomes mais comuns por origem étnica.

\footnotetext{
${ }^{5}$ Nos registros telefônicos, encontraram-se os sobrenomes Silva e da Silva. Para fins operacionais, ambos foram considerados sinônimos. Neste artigo, far-se-á referência sempre à forma Silva.

${ }^{6}$ Nos registros telefônicos, encontraram-se os sobrenomes Santos e dos Santos. Para fins operacionais, ambos foram considerados sinônimos. Neste artigo, far-se-á referência sempre à forma Santos.

${ }^{7}$ Nos registros telefônicos, encontraram-se os sobrenomes Oliveira e de Oliveira. Para fins operacionais, ambos foram considerados sinônimos. Neste artigo, far-se-á referência sempre à forma Oliveira.

${ }^{8} \mathrm{O}$ sobrenome Schmidt é também encontrado como Schmitt. Para fins operacionais, ambos foram considerados sinônimos.

${ }^{9}$ Nos registros telefônicos, encontraram-se os sobrenomes Rosa e da Rosa. Para fins operacionais, ambos foram considerados sinônimos. Neste artigo, far-se-á referência sempre à forma Rosa.
} 
Já em relação aos números absolutos, dos 20 sobrenomes com maior frequência, ocorre uma pequena inversão, pois há mais sobrenomes de origem portuguesa que de origem alemã. Das 1.223 ocorrências, há 529 de origem alemã, 651 de origem portuguesa e 43 de origem italiana, o que corresponde a 43,25\%, 53,22\% e 3,53\%, respectivamente (Gráfico 02).
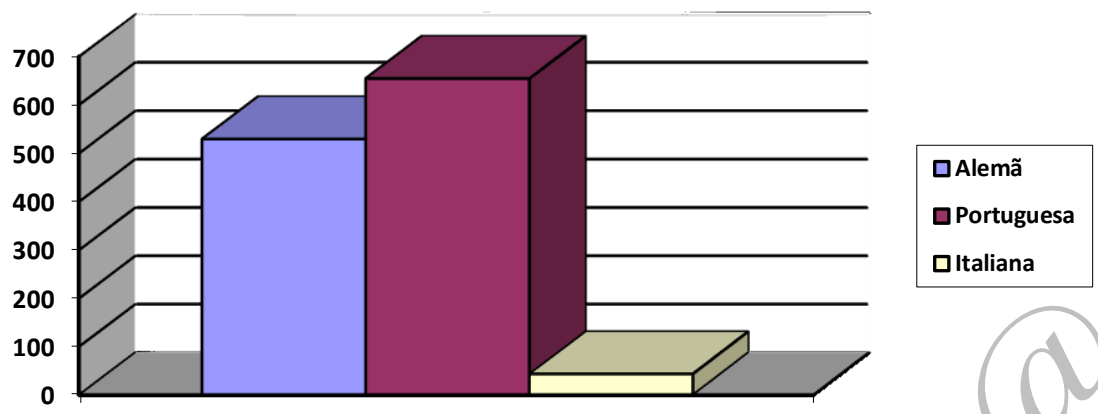

Gráfico 02 - Os 20 sobrenomes mais comuns por origem étnica em números absolutos.

Levando-se em conta a tipologia dos sobrenomes, identificaram-se algumas categorias, tais como sobrenomes alusivos a profissões: Mallmann, Schneider, Schmidt, Becker, Scherer, Müller, respectivamente juiz, alfaiate, ferreiro, padeiro, tosquiador, moleiro; de origem geográfica: Silva, Oliveira, Souza, Costa e Ferreira, respectivamente selva, árvore da azeitona, seixos, costa do mar, jazida de ferro; patronímicos: Rodrigues e Lopes; sobrenomes usados como nomes: Johann e Rosa; de origem religiosa: Santos; alcunha: Klein, entre outros, como Eckhardt, Pretto e Gerhardt. (Gráfico 03).

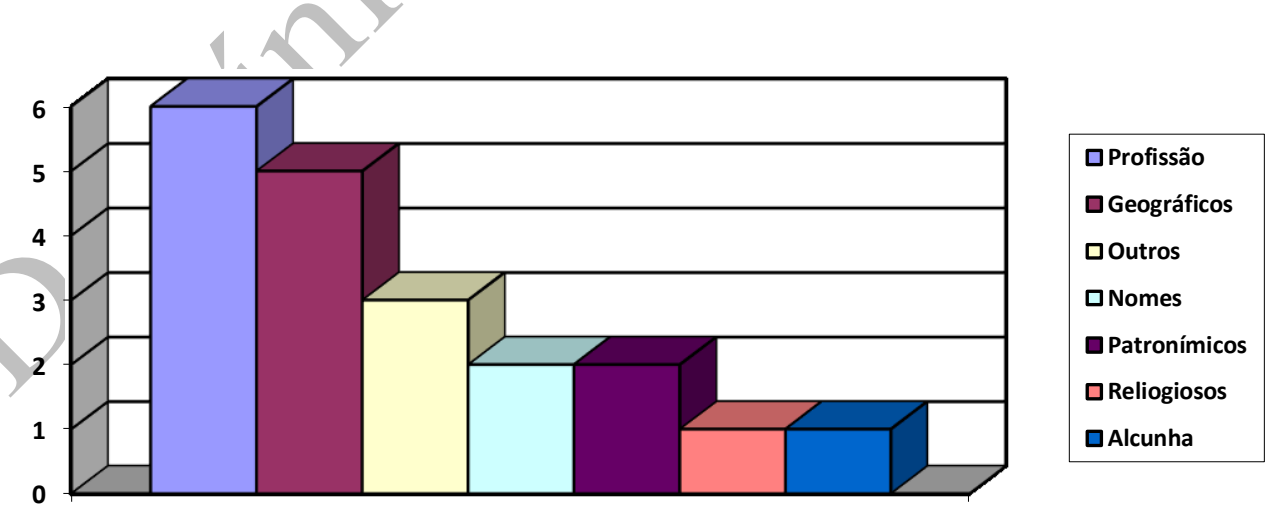

Gráfico 03 - Os 20 sobrenomes mais comuns por tipologia.

Tomando como corpus de análise os 20 sobrenomes com maior frequência, far-se-á, a seguir, uma análise histórico-etimológica de cada um deles. Também serão estabelecidas 
comparações com dados numéricos do Rio Grande do Sul, com base num estudo realizado por Klering ${ }^{10}$ (1988) na Companhia de Processamento de Dados do Estado do Rio Grande do Sul.

SILVA - É o sobrenome mais comum de Lajeado, do Rio Grande do Sul e do Brasil. Guérios (1973) explica que o sobrenome é de origem geográfica e que deriva do termo latino silva, que significa selva ou floresta. Para Barata e Bueno (1999), também é de origem geográfica, especialmente para os que não são de sangue azul. Segundo os autores, o registro mais antigo que se tem no Brasil é de 1612 em São Paulo, da família de Pedro da Silva, um alfaiate vindo de Portugal. No Rio Grande do Sul, a família de Antônio da Silva Caldeira, que veio da Ilha de Madeira, é o registro mais antigo, datado de 1735.

SANTOS - É o segundo sobrenome mais comum de Lajeado, do Rio Grande do Sul e do Brasil. É um sobrenome de origem religiosa que deriva da palavra latina sanctus e que significa santo ou consagrado. Uma segunda hipótese é que o sobrenome tenha se originado do topônimo Sierra de los Santos, localizado na Andaluzia, no sul da Espanha. Santos também era dado como nome, por tradição na era medieval, às pessoas que nasciam no dia $1^{\circ}$ de novembro, isto é, no dia de "Todos os Santos". No Brasil, é um sobrenome espalhado por todos os estados e o registro mais antigo de que se tem notícia é de 1645, no Rio de Janeiro, com a família de Antônio dos Santos (BARATA; BUENO, 1999).

MALLMANN - É o sobrenome de origem alemã com mais ocorrências em Lajeado. É também, de acordo com Klering (1988), um dos sobrenomes alemães mais comuns no Rio Grande do Sul. O sobrenome é formado por duas palavras: "Mann significa homem. O termo Mall desapareceu da língua alemã. Entre os francos, povo de raça germânica que invadiu a Gália, significou tribunal. Mallmann talvez fosse o juiz ou aquele que manteve em ordem o lugar do julgamento", conforme dados encontrados em www.mallmann.jur.adv.br (2012, grifos nossos). Segundo Barata e Bueno (1999), a primeira família Mallmann estabeleceu-se no Brasil em 1845, por ocasião da colonização do município de Petrópolis, no Rio de Janeiro.

SCHNEIDER - Além de ser o segundo sobrenome de origem alemã mais comum de Lajeado, é também um dos sobrenomes alemães mais comuns no Rio Grande do Sul, segundo Klering (1988). De acordo com Guérios (1973), é um sobrenome tomado de profissão, uma vez que Schneider significa, literalmente, alfaiate. Para Barata e Bueno (1999), a primeira família com esse sobrenome estabeleceu-se em Petrópolis, no Rio de Janeiro, em 1845 quando da

\footnotetext{
${ }^{10}$ Para estimar os nomes mais comuns do Rio Grande do Sul. O autor utilizou uma amostra de 951.645 pessoas, o que correspondia, na época, a $10,72 \%$ da população total do Estado.
}

(C) Kleber Eckert, p. 139-159 
colonização do município. Já no Rio Grande do Sul, o primeiro registro do sobrenome dá-se em 1851, quando uma família de origem prussiana estabeleceu-se no Estado.

OLIVEIRA - É o terceiro sobrenome de origem portuguesa mais comum de Lajeado e também o terceiro do Rio Grande do Sul (Klering, 1988). Para Guérios (1973), é um sobrenome geográfico que remete à árvore da azeitona, que era registrado no português arcaico como Olveira ou Ulveira. Segundo Barata e Bueno (1999), o sobrenome é de origem toponímica, originado de alguma propriedade onde se cultivavam oliveiras. No Brasil, a data mais antiga de que se tem notícia do sobrenome é de 1617, por ocasião do casamento de Bento de Oliveira. No Rio Grande do Sul, em 1734 têm-se registros da família de Domingos Fernandes de Oliveira (BARATA; BUENO, 1999).

SCHMIDT - É o terceiro sobrenome de origem alemã com mais ocorrências em Lajeado. E no Rio Grande do Sul é, de acordo com Klering (1988), o sobrenome alemão que mais ocorre do Estado. Conforme Barata e Bueno (1999), é um sobrenome tomado de profissão, uma vez que Schmidt significa, literalmente, ferreiro. Conforme esses autores, onze famílias germânicas com esse sobrenome estabeleceram-se em Petrópolis, no Rio de Janeiro, em 1845, quando da colonização do município.

BECKER - É o quarto sobrenome de origem alemã com mais ocorrências em Lajeado e, de acordo com Klering (1988), o segundo no Rio Grande do Sul. Para Guérios (1973), é um sobrenome que se origina de profissão, pois significa, literalmente, padeiro. Barata e Bueno (1999), no entanto, apresentam duas explicações para a formação do sobrenome. No norte da Alemanha, Becker significa ribeirão e somente no sul tem o significado de padeiro. Para Barata e Bueno (1999), a primeira família Becker estabeleceu-se em Petrópolis, no Rio de Janeiro, em 1845 quando da colonização do município. Já no Rio Grande do Sul, o primeiro registro do sobrenome dá-se em 1869, quando Karl Becker estabeleceu-se em São Leopoldo.

SOUZA - É o quarto sobrenome de origem portuguesa com mais ocorrências em Lajeado e o quarto mais comum do Rio Grande do Sul (KLERING, 1988). É um sobrenome que tem por significado original "seixos" ou "rochas", que vem do latim Saxa [Saksa]. A forma latina, por sua vez, divide-se em duas formas que entram no português arcaico por volta do século XI: Sausa e Seixas. A primeira delas evolui, em Portugal, para Sousa e mais tarde, no Brasil, passa a ser registrada também como Souza. Em Portugal, sousa é também uma espécie de pombo bravo, cujo sinônimo é seixa (GUÉRIOS, 1973). Para Barata e Bueno (1999), o sobrenome foi usado por uma das mais antigas e ilustres famílias de Portugal e o primeiro a 
adotá-lo foi Dom Egas Gomes de Souza, que era o dono do Solar de Souza. Martin Afonso de Sousa, comandante da expedição que fundou o primeiro núcleo de colonização e donatário da capitania de São Vicente, foi seu $12^{\circ}$ neto. Dom Egas era primo de Tomé de Souza, o primeiro governador-geral do Brasil.

SCHERER - É o quinto sobrenome de origem alemã mais comum em Lajeado e, de acordo com Klering (1988), o oitavo mais comum do Rio Grande do Sul. Para Guérios (1973), é um sobrenome alemão que tem dois significados, ambos originados de profissões: tosquiador de lã ou cortador de tecidos. O autor ainda apresenta uma terceira possibilidade de interpretação, que vem do baixo alemão, e que significa guarda florestal. Conforme Barata e Bueno (1999), há vários registros do sobrenome no Brasil a partir da vinda dos imigrantes alemães. A primeira família teria se estabelecido em 1845 em Petrópolís, no Rio de Janeiro, por ocasião da colonização do município. Após, por volta de 1900, há registros de famílias que se estabeleceram onde atualmente localizam-se os estados do Rio Grande do Sul, Santa Catarina e Paraná.

RODRIGUES - É o quinto sobrenome de origem portuguesa com maior ocorrência em Lajeado e também o quinto do Rio Grande do Sul, segundo Klering (1988). É um sobrenome comum na Península Ibérica que tem origem no patronímico de Rodrigo, isto é, filho de Rodrigo. Em espanhol, escreve-se Rodríguez (GUÉRIOS, 1973).

ECKHARDT - É o sexto sobrenome de origem alemã com mais frequência em Lajeado. Até onde foi possível saber, não se encontrou o significado do sobrenome, embora por hipótese se possa inferir que signifique algo como "canto e/ou esquina + duro(a)". Segundo Barata e Bueno (1999), é de 1823 o primeiro registro do sobrenome, de uma família germânica estabelecida em Nova Friburgo, região serrana do Rio de Janeiro. O sobrenome também era registrado, de acordo com os autores, como Eccard, na forma afrancesada; Ecardo na aportuguesada; e Eckard, em forma adulterada. Em Lajeado, encontraram-se as variantes Eckardt e Eckhart.

PRETTO - É o sobrenome de origem italiana com maior frequência em Lajeado. Conforme Caffarelli e Marcato (2008), é um sobrenome que é típico do norte da Itália, da região do Vêneto. Para os autores, o sobrenome é resultado de ilhas linguísticas germânicas, por tratarse de uma adaptação do sobrenome germânico Precht que, por sua vez, é uma abreviação do sobrenome medieval Adelprecht. No Brasil, além do sobrenome de origem italiana, registra-se 
também o sobrenome Preto (com um 't') de origem portuguesa, que era primitivamente uma alcunha para fazer referência à cor da pele (BARATA; BUENO, 1999).

JOHANN - É o sétimo sobrenome de origem alemã com maior frequência em Lajeado. A forma Johann significa, literalmente, João e, por isso, é usada, na língua alemã, como nome e como sobrenome. Guérios (1973) apresenta a etimologia do sobrenome a partir do hebraico: "Iehohanan, Iohanan: Javé (Ieho) é (cheio) de graças (hanan). Ou Javé é misericordioso. Outros: Javé deu, presenteou" (p. 135, grifos do autor).

COSTA - É o sexto sobrenome de origem portuguesa ${ }^{11}$ mais frequente em Lajeado e, segundo Klering (1988), o décimo sobrenome mais comum do Rio Grande do Sul. É um sobrenome de origem geográfica usado, na origem, na orografia. Para Barata e Bueno (1999), o número de famílias com o sobrenome Costa que passaram para o Brasil foi alto e ocorreu em ocasiões diversas. "Não se pode considerar que todos os Costas existentes no Brasil, mesmo procedentes de Portugal, sejam parentes, porque são inúmeras as famílias que adotaram este sobrenome pela simples razão de ser de origem geográfica, ou seja, tirado do lugar de Costa" (p. 788).

ROSA - É o sétimo sobrenome de origem portuguesa mais frequente em Lajeado e, de acordo com Klering (1988), o nono sobrenome mais comum do Rio Grande do Sul. Para Mioranza (2009), o sobrenome vem do nome feminino Rosa, que se originou da forma latina rosa, que é a flor da roseira. "Transformado no final do Império Romano em nome próprio de bons vaticínios, conferido à filha com os votos de que crescesse bela, formosa, delicada e perfumada como essa flor, difundiu-se ainda mais no período medieval em função do culto prestado a diversas santas chamadas Rosa” (MIORANZA, 2009, p. 169). No Rio Grande do Sul, o primeiro registro que se tem do sobrenome remonta ao ano de 1816, com a família de Luiz Antonio da Rosa, que veio de ilhas portuguesas (BARATA; BUENO, 1999).

MÜLLER ${ }^{12}$ - É o oitavo sobrenome de origem alemã com mais ocorrências em Lajeado e, segundo Klering (1988), o quarto do Rio Grande do Sul. Segundo Guérios (1973), é um sobrenome alemão que se originou da profissão de moleiro, pois em alemão moinho escrevese mühle. De acordo com Barata e Bueno (1999), no Brasil, há diversas famílias que possuem

\footnotetext{
${ }^{11}$ O sobrenome Costa pode ser considerado, conforme Barata e Bueno (1999), tanto de origem portuguesa quanto italiana, uruguaia e espanhola. Neste trabalho, por não ter havido a possibilidade de separá-lo em grupos, ele foi considerado, por motivos operacionais, de origem portuguesa.

${ }^{12}$ Guérios (1973) registra outras formas do sobrenome Müller: Mühler, Mülder, Môlter, Môller, Müllner, Milner e Miller.
} 
esse sobrenome, que estão espalhadas nas regiões sul e sudeste. A primeira família com o sobrenome Müller estabeleceu-se no Rio de Janeiro no século XVIII.

GERHARDT - É o nono sobrenome de origem alemã com mais ocorrências em Lajeado. Etimologicamente, é formado por dois elementos que podem ser traduzidos por "lança forte" ou "forte como uma lança" (GUÉRIOS, 1973). No Brasil, a primeira família com esse sobrenome estabeleceu-se em Petrópolis, no Rio de Janeiro, por ocasião de sua colonização, em 1845 (BARATA; BUENO, 1999).

FERREIRA - É o oitavo sobrenome de origem portuguesa mais frequente em Lajeado e, conforme Klering (1988) o décimo primeiro do Rio Grande do Sul. Segundo Guérios (1973), Ferreira é um sobrenome de origem geográfica que significa "lugar onde há ferro, mina ou jazida de ferro - observado pelos romanos ou luso-romanos, em terrenos da Lusitânia” (p. 107). O registro mais antigo de que se tem notícia remonta ao século XI, quando, em Portugal, Rio Pires usou o sobrenome Ferreira ao tomar a localidade de Ferreira de Avis, onde se tornou senhor e fundou o solar da família (BARATA; BUENO, 1999).

KLEIN - É o décimo sobrenome de origem alemã mais comum em Lajeado e, segundo Klering (1988), um dos mais comuns do Rio Grande do Sul. É um sobrenome que era usado, primitivamente, como alcunha, cujo significado é "pequeno". No Brasil, a primeira família Klein estabeleceu-se em Petrópolis, no Rio de Janeiro, por ocasião da colonização do município, em 1845 (BARATA; BUENO, 1999).

LOPES - É o décimo sobrenome de origem portuguesa com mais ocorrências em Lajeado e, de acordo com Klering (1988), um dos mais comuns do Rio Grande do Sul. Lopes é um sobrenome que se formou do patronímico de Lopo, ou seja, filho de Lopo. A forma lopo, que derivou do latim lupus, significa lobo (GUÉRIOS, 1973). No Brasil, assim como os demais patronímicos antigos, o sobrenome Lopes se espalhou por todo o território desde os primeiros anos de povoamento. No Rio Grande do Sul, o registro mais antigo remonta ao ano de 1738 , com a família de Pedro Lopes (BARATA; BUENO, 1999).

\section{Considerações Finais}

A partir do levantamento dos 20 sobrenomes mais comuns do município de Lajeado podem-se tecer algumas notas conclusivas. O primeiro aspecto a ser analisado é a questão da dessemantização, que é a perda do conteúdo semântico do item lexical original. Se olharmos a lista dos 20 sobrenomes em destaque, percebe-se que muitos deles ainda possuem o mesmo 
significado que tinham no momento em que surgiram. Com outros, no entanto, ocorreu a dessemantização, como o sobrenome Mallmann, que significava "juiz ou aquele que mantém em ordem o lugar do julgamento". Além da palavra Mallmann não ter mais o significado que tinha quando surgiu, atualmente, o termo Mall nem mais existe na língua alemã.

Em relação à dessemantização do antropônimo, Carvalinhos (2007) afirma que "como a língua é naturalmente dinâmica, o nome é rapidamente esvaziado de seu real significado etimológico, restando apenas um invólucro, uma forma opaca que oculta o verdadeiro significado original do nome" (p. 03).

Portanto, em relação a alguns sobrenomes, torna-se difícil alcançar 0 significado original, pois alguns deles podem ter surgido, inclusive, por um viés metafórico. $\mathrm{E}$ assim como algumas palavras tendem a ser deixadas de lado e, após, esquecidas, as metáforas mais antigas também são difíceis de serem reconhecidas, conforme preconiza Bréal (1992): "a lembrança da metáfora é tão completamente esquecida que se engana a respeito dela" (p. 92). E o que pode acontecer também é que "o estado de coisas que as tinha sugerido, tendo desaparecido, fica-se diante de uma raiz de significação incolor" (p. 95).

O segundo ponto a ser levado em conta guarda relação com a história da localidade. Dos 20 sobrenomes mais frequentes localizados na lista telefônica de 2012, percebe-se uma supremacia dos antropônimos de origem alemã e portuguesa, em detrimento aos de origem italiana. O fato pode ser analisado à luz da história de ocupação e colonização de Lajeado, uma vez que a localidade foi fundada por portugueses por volta de 1800 , quando os irmãos João e José Inácio Teixeira receberam sesmarias e as dividiram em fazendas. Meio século mais tarde, Fialho de Vargas comprou as terras dos irmãos Teixeira e vendeu pequenos lotes a colonos alemães.

Entre os 20 sobrenomes mais frequentes apareceu somente 1 de origem italiana, que é o antropônimo Pretto. Apesar de Lajeado não ter sido colonizado diretamente por italianos ou seus descendentes, é preciso referir aqui que o município, que hoje possui $90 \mathrm{~km} 2$, era dez vezes maior no ato de sua emancipação, em 1891, e abarcava uma região onde atualmente localizamse 11 outros municípios. Entre eles, vários que foram colonizados por descendentes de imigrantes italianos, num processo que Frosi e Mioranza (2009) chamam de correntes migratórias internas.

Também acerca da tipologia dos sobrenomes pode-se chegar a uma síntese. Dos 10 sobrenomes de origem alemã, 6 indicam alguma profisssão, como Mallmann, Schneider, 
Schmidt, Becker, Scherer e Müller, enquanto dos sobrenomes de origem portuguesa, nenhum faz referência a profissões. Por outro lado, dos 9 sobrenomes portugueses estudados, 5 têm na sua formação uma origem geográfica, como Silva, Oliveira, Souza, Costa e Ferreira, enquanto nenhum dos sobrenomes germânicos estudados apresentou origem geográfica.

Por fim, o breve levantamento feito acerca dos sobrenomes que possuem maior frequência em Lajeado mostra, indiretamente, a história de ocupação e colonização desta localidade. A partir dos sobrenomes, pode-se contar a história de uma comunidade, identificar a origem étnica dos habitantes e, se o estudo for feito de tempos em tempos, pode-se até identificar se há correntes migratórias de uma região para outra.

\section{Referências}

BARATA, C. E.; BUENO, A. H. da C. Dicionário das famílias brasileiras. São Paulo: Ibero América, 1999. 2 v.

BRÉAL, M.. Ensaio de semântica: ciência das significações. São Paulo: EDUC, 1992.

CAFFARELLI, E.; MARCATO, C. I cognomi d'Italia; dizionario storico ed etimologico. Torino: UTET, 2008. 2 v.

CARVAlinhos, P. de J. As origens dos nomes de pessoas. In: Domínios de Lingu@gem, Ano $1, \quad \mathrm{n}^{\mathrm{o}} \quad 1, \quad 1^{\circ}$ Sem. de 2007, disponível em http://www.seer.ufu.br/index.php/dominiosdelinguagem. Acesso em: 27 de mar. de 2013.

DAUZAT, A. Les noms de personnes: origen et évolution Prénoms - Noms de famille Surnoms. 4 ed. Paris: Delagrave, 1950.

DICK, M. V do A. Toponímia e Antroponímia no Brasil: Coletânea de Estudos. 3 ed. São Paulo: Serviços de Artes Gráficas do FFLCH, 1992.

A Investigação Linguística na Onomástica Brasileira. In: Estudos de Gramática Portuguesa III. Frankfurt am Main, v. III, 2000.

FROSI, V. M.; MIORANZA, C. Imigração Italiana no Nordeste do Rio Grande do Sul: processos de formação e evolução de uma comunidade ítalo-brasileira. 2 ed. rev. e aum. Caxias do Sul: Educs, 2009.

GUÉRIOS, R. F. M. Dicionário Etimológico de Nomes e Sobrenomes. 2 ed. São Paulo: Ave Maria, 1973. 
KLERING, L. R. Nomes mais comuns na terra do Rio Grande do Sul (RS). (1988). Disponível em: www.terragaucha.com.br/nomesRS. Acesso em: 16 de out. 2012.

MARCATO, C. Nomi di persona, nomi di luogo: introduzione all'onomastica italiana. Bologna: il Mulino, 2009.

MIORANZA, C. Filius Quondam: a origem e o significado dos sobrenomes italianos. 2 ed. São Paulo: Larousse, 2009.

ROSSEBASTIANO, A.; PAPA, E. I nomi di persona in Italia: dizionario storico etimologico. Torino: UTET, 2005.

SEABRA, M. C. T. C. de. Referência e Onomástica. In: Múltiplas Perspectivas em Linguística. MAGALHÃES, J. S. de; TRAVAGLIA, L. C.. (org.). Uberlândia: Edufu, 2008, p. 1945-1952. Disponível em: http://www.filologia.org.br/ileel/artigos/artigo_442.pdf. Acesso em 27 de mar. 2013.

SECULTUR - Secretaria de Cultura e Turismo de Lajeado. Descobrindo Lajeado: aspectos históricos, culturais, paisagísticos e muito mais... Caxias do Sul: Mercoplan, 1997.

SHIERHOLT, J. A.. Lajeado II: APEUAT - raízes do ensino superior. Lajeado: J.A. Shierholt, 1995.

Imigração italiana no Vale do Taquari. In: Anais do I e II Simpósios Raízes do Vale. Lajeado: Grafocem, 2000, p. 92.

<www.mallmann.jur.adv.br.> Acesso em: 29 de dez. 2012.

<www.ibge.gov.br/cidadesat/topwindow.> Acesso em: 02 de jan. 2013.

Artigo recebido em: 22.02 .2013

Artigo aprovado em: 14.04.2013 